\title{
Views of lecturers and students on e-learning (from Economics Network surveys)
}

\section{From the 2003 and 2005 lecturers surveys:}

\section{Use of technology in your teaching}

Questions regarding the use of technology in teaching were included in both the 2003 and 2005 Surveys. This has allowed us to track the changes in this area over the intervening period. Lecturers were asked what technological medium they used to communicate with the students. In 2005 nearly half of them (46\%) replied that they use a Virtual Learning Environment (Blackboard, WebCT, etc.), while a quarter of them use departmental websites, and slightly fewer - about one in five - use e-mails. The remaining $7 \%$ use either shared folders or other technological media.

Figure 4 Use of technological media by respondents for communicating with students

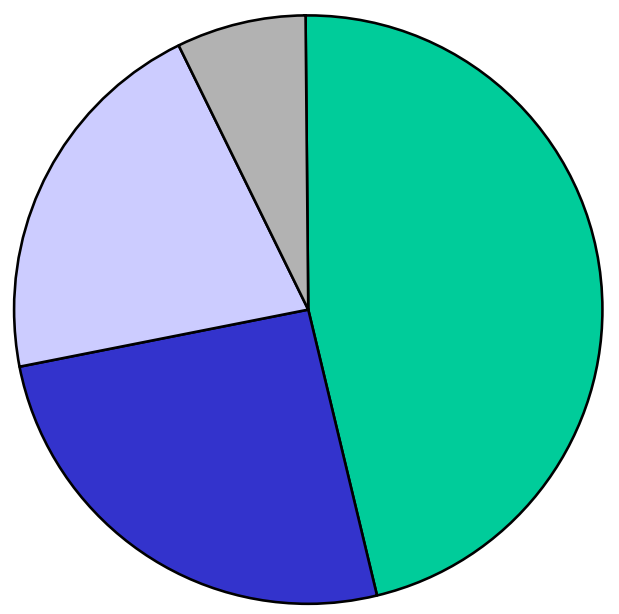

\begin{tabular}{|l|}
$\square$ VLE \\
$\square$ Departmental websites \\
$\square$ e-mails \\
$\square$ Shared folders and \\
other
\end{tabular}

Respondents' replies regarding the possible use of various activities on the VLE or departmental web site for individual courses/modules are summarised in the table below. All the data is in percentages, where $100 \%$ is equal to all lecturers who replied to this question (roughly about 160 replied for this question).

Table 1. VLE features or departmental web activities respondents use now or my consider in the future (\%)

\begin{tabular}{|l|c|c|c|}
\hline Teaching activity & Use now & $\begin{array}{c}\text { May } \\
\text { consider }\end{array}$ & $\begin{array}{c}\text { Will not } \\
\text { consider }\end{array}$ \\
\hline Delivering learning resources & 81 & 15 & 4 \\
\hline Communicating with learners & 72 & 21 & 5 \\
\hline Supporting discussion & 19 & 53 & 28 \\
\hline Tracking the progress of learners & 19 & 57 & 25 \\
\hline Providing online formative assessment & 23 & 60 & 18 \\
\hline
\end{tabular}




\begin{tabular}{|l|r|r|l|}
\hline Conducting online summative assessments & 9 & 58 & 33 \\
\hline Collecting student submissions & 16 & 64 & 20 \\
\hline Supporting peer or self-assessment & 6 & 61 & 33 \\
\hline Supporting personal development planning & 7 & 59 & 34 \\
\hline
\end{tabular}

Comparing these data to the results of 2003 survey, there has been a significant increase in the use of technology in teaching economics. More of the lecturers are now using a VLE or departmental web sites in their teaching (58\% of the respondents used it in 2003 and $87 \%$ in 2005). VLEs are also used in more creative ways: their use for communication with learners has increased from $40 \%$ to $72 \%$ and for online assessment from $17 \%$ to $23 \%$. They are used for tracking the progress of learners, supporting PDPs, and "providing means to do independent and self-driven studying and research", as one of the respondents put it. Though, as we can see from the table, respondents still mostly use VLEs for delivering learning resources.

It is important for us to know not only what features of VLEs respondents are using already, but also what they are considering or not considering using in the future and why. One in six respondents use it for collecting students' submissions, while more than three out of five may consider using it for this purpose in the future. More than half of the respondents who are currently not using VLEs for various teaching activities may consider doing so in the future. About a third of respondents are not considering using a VLE to support personal development planning, peer or selfassessment or conducting online summative assessments. The main reason for that is the same as 2 years ago: time constraints. Only a few of the respondents doubt the benefits of different aspects of technology to the students.

We also asked lecturers about those aspects of technology that are available to them, but which they are currently not using and why. In their answers respondents mostly mentioned some facilities of Blackboard and WebCT that they are not using now, and agree that they could use more of them. Amongst other mentioned aspects were interactive whiteboards, personal response systems, Questionmark Perception software and short message texting. Some of the lecturers mentioned that they do not use PowerPoint slides.

Respondents provide detailed remarks about the reasons why they do not use all the facilities, available to them. These reasons could be divided into several groups:

A. No time

- They are VERY time consuming and the payoff is low

- No time to invest in sunk cost required

- Time constraints for setting up courses

B. No skill

- Lack of development time

- Need coaching to be sure which are available, as well as how

- Too much investment in learning how to use for marginal gain in delivery to students over what I do at present

C. Technology is not reliable 
- No technical back-up

- Still not $100 \%$ confident of robustness of network

- Unreliable, does not look professional

D. Students don't use them

- Virtual office hours - students ignored them

- Students tend not to use them

E. Not impressed with it

- Do not find it useful

- I have not found the system to be very user friendly

- Learning technologies are a poor substitute for real physical contact with students

- Prevents teaching and interaction

F. Lack of awareness of existing resources

- Not aware of useful materials in my area and very time consuming to create

- Not sufficiently developed for math

G. PowerPoint is not an effective tool

- It doesn't enable the development of an argument

- Students often disengage if classes are over reliant on PP

- They deter students from taking their own notes which is very important cognitive step in the learning process

The majority of respondents mentioned two of the suggested reasons - lack of time and skill. Providing resources that could ease the use of various aspects of technology in teaching will be one of the targets of the Economics Network in the coming year.

Given various services, which could be provided by the Economics Network in respect to the use of technology, the respondents were asked to rank their priority, with 1 as most valuable. The average ranks can be seen in Table 2 .

Table 2. Average rank of the desirable services that could be provided by Economics Network, with 1 as most valuable

\begin{tabular}{|l|c|}
\hline Service & Rank \\
\hline Information about the new technologies that are available in Economics & 2.4 \\
\hline Access to peer-reviewed learning resources & 2.7 \\
\hline Staff development in using new technologies to support effective learning & 3.1 \\
\hline $\begin{array}{l}\text { Guidelines, case studies and publications relating to the effective use of e- } \\
\text { learning }\end{array}$ & 3.2 \\
\hline Opportunities to share ideas and experiences with colleagues & 3.3 \\
\hline
\end{tabular}


Nearly half of the respondents rank provision of 'Information about the new technologies that are available in Economics' as most valuable. Slightly less valuable they find 'Access to peer-reviewed learning resources', while 'Staff development in using new technologies to support effective learning' is in third place. The Economics Network will use this information in prioritising the development of resources and provision of workshops in the coming year.

\section{From the 2007 lecturers survey}

A quarter of lecturers in the survey mention developments in technology and elearning as one of the reasons for their change in teaching practice in the last two years.

Quotes from the survey:

- Use of one Macroeconomics computer-based learning package and one statistics computer-based learning package

- I am increasingly adopting a "blended learning" approach to delivery

- Had a graduate teaching assistant who managed to to put the weekly quizzes on WebCT despite their unusual format

- I have developed a particular practice over the last few years that seems to work well in the sense of pass rates and student feedback. This involves OHP slides that are also given to students in hard copy (with white space for annotation). These are available on the website in pdf form. Computer demonstrations are also made to demonstrate tasks conducted in computer workshops where students follow guide notes having observed elements of the exercise. Class exercises set by the lecturer but led by students in class. Answers are provided on the website with at least one week lag

- I continue to update short video clips to illustrate theory and practice

- I've moved to a more learner-centered teaching model. Also, use of social software: blogs, wikis, RSS, etc

- $\quad$ PPT presentations have made my teaching for this particular module more effective and, I believe, more interesting from the student's point of view. However, I have not introduced PPT for the other two modules I am teaching, as they are more analytical and, I think, using the whiteboard to derive the models' solutions step by step is a more rigorous teaching approach

- Provided summary lecture notes on the web

- We are running a pilot for the use of the turnitin plagiarism analysis software -all courses will have to use it next year Also from next year all courses are going to have to use the WebCT Vista VLE

\section{Student's views on e-learning}

In our 2006 survey we ask students how effective they have found online learning in supporting their learning and how the effectiveness could be improved.

From the survey report: 


\section{Q13.j. - 13.n. Online learning}

The next five questions were dedicated to various types of online learning. There are many similarities in the way students' answers these group of questions.

Many forms of online learning are still unavailable to big groups of students: thus every fifth respondent didn't have online learning using the Web available and two fifth of respondents didn't have online learning using Economics software and online questions and tests (not assessed) available.

Use of Virtual Learning Environments (VLEs) is spread more widely: only less than one in ten respondents didn't have materials posted by lecturer on course VLEs or website.

At the same time VLEs are not used interactively: communication tools (e.g. discussion board) are not available to every third respondent.

More than half of those who have these forms of online learning available to them find them useful, with the exemption of communication tools in course VLEs, where the majority of $38.9 \%$ find it of some or little use.

Among the factors that affected students' replies were year of study, age and gender, choice of degree and first language. Some of these differences could be explained by the preferences of a lecturer or a department in using particular types of online learning for a particular course (year of study), some by the gender preferences in the use of online learning (other studies support this result (http://sole.ilrt.bris.ac.uk/findings.html)). Those differences though being statistically significant are not very big in absolute terms. However the differences in availability of 'Online learning using the web' and 'Materials posted by lecturer on VLEs' to the mature students of 26 and older are nearly as twice as much as for the rest of the age groups and demands further investigation. Unfortunately this group of students hasn't provided many additional comments that could clarify this issue. Among the submitted ones - "My problem was mostly with access to it, due to not living on campus and not having broadband internet at home."; "Some news could be made much more clear and more materials should be put to use."; "As I am a part time student, I often need to travel for work. I would really like to be able to attend my lectures via the web.”; “I can’t use it.”

Potentially these striking differences in the results could be caused by the following:

A. Availability of computers - many mature students live off-campus and thus lack the access to the computers on-site; some of them may have families and other material obligations and don't own a computer; a majority of them also work to support themselves and their families and may not necessarily have a computer at work or time to use it for study.

B. Confidence in the use of computers, which may be due to lack of access. Many mature students with less experience then their younger counterparts, might lack computer skills and confidence in the use of online materials, they are not so called "digital natives" (3). Materials may be posted on a VLEs or departmental website and are available to students if they know where to look for it, but if they are not computer literate they won't be aware of these resources.

Departments ought to consider whether this affects the learning possibilities of their mature students. 'Internet Economist,' an online tutorial provided by the Economics Network may help develop students' skills and confidence with online resources: 


\section{Q13.j. Online learning using the Web}

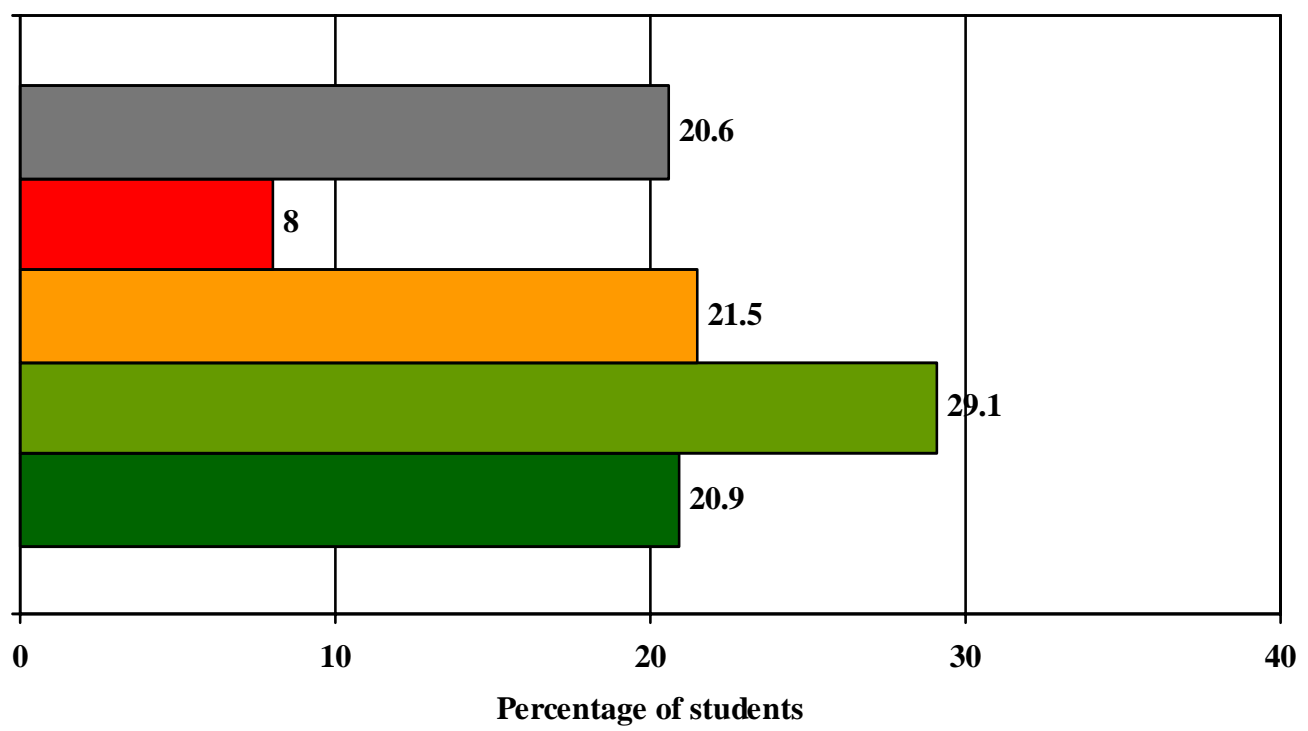

$\square$ Very useful $\square$ Useful $\square$ Of some use $\square$ Of little use $\square$ N/A

Half of all respondents and $62.4 \%$ of those who have it available to them, find online learning using the Web useful. There were differences in students' replies due to the year of study and age. Most positive about online learning were first and fourth year students $53.9 \%$ and $53.4 \%$ respectively (or $66.3 \%$ and $68.6 \%$ of those who were offered that type of learning). Two out of five postgraduates find it useful, although this number growth to more than three out of five if availability is taken. Differences in students' perceptions of online learning due to their age are mainly concerned with the availability of these types of activities. As previously discussed the nonavailability of online learning using the web for the mature group of students of 26 and older is double to that of other age groups and equal to 35.9\%. Even those of them, who have it available, were the least positive about online learning among all age groups $-57.7 \%$ compared to $63.9 \%$ of $18-21$ year olds and $60.7 \%$ of $22-25$ year olds. Younger students are more accustomed to the use of computers in their everyday life and see online learning as an essential part of it, while it could be a struggle to the mature students due to the factors discussed above.

Among the students' comments: "Annoying to access.”; “Can't find the exact book.”; "Good depending on lecturer.”; "This isn't offered but would be a great help.”; "Very useful in first year, as it was interactive."; "Online learning using the Web can help me learn more."; "Online learning using the Web, because we will always use the internet to look for sorts of information any time any place. It's so useful.” 


\section{Q13.k. Online learning using Economics software}

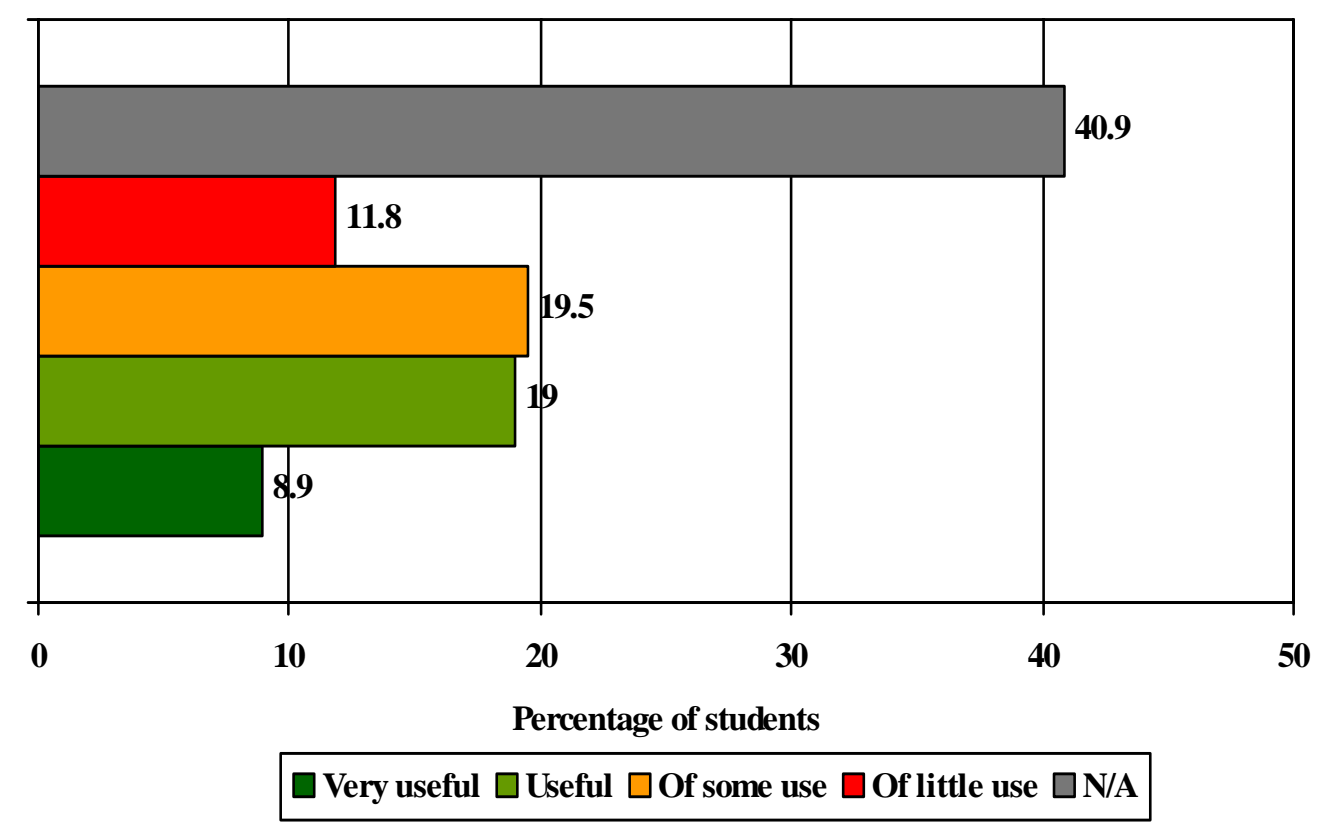

Online learning using Economics software was not available to two out of five respondents. Those who have it available were split into two nearly equal groups of those who consider it to be useful (46.6\%) and others, who see in it only some or little use (53.4\%). Many factors were statistically significant for this question: year of study, gender, age, first language and first choice of degree.

Postgraduates were the most positive group: $58.7 \%$ of them, who have it available, find it useful. Least positive were second and third year students - 61.1\% and 59.2\% of those, who have it available, find it only of some or little use

Students who study Economics as their first choice were more positive then those who don't $-48.7 \%$ and $40.8 \%$ of those who have it available find it useful.

Females were more positive than males in finding Economics software useful: $50.7 \%$ compared to $44.4 \%$ of males.

Those with English as first language were less positive, then respondents with other first language: $45.8 \%$ versus $49.8 \%$.

Most positive about use of software were mature students, who started university at 26 or older: $58.3 \%$ of them, who have it available, find it useful, compared to $45.1 \%$ of $18-21$ year olds and $52.5 \%$ of $22-25$ year olds. This is in contrast to the respondents' answers to the previous question regarding online learning using the web, when mature students were the least positive. It could be due to the fact that all groups of students were new to the use of Economics software and have to learn it from scratch; whilst with online learning younger students were more frequent users of the web.

In the comments many students point to the lack of availability of this type of activity to them: "Haven't really used it yet."; "I don't have one at the moment, but would love to have."; "Not part of the course but I have used economic software anyway and have found it very useful." 
The survey also included open-ended questions Q21 and Q21.a. regarding the types of Economics software being used in degrees and asks students to comment about its usefulness. They are analysed later in the report.

\section{Q13.l. Online questions and tests (not assessed)}

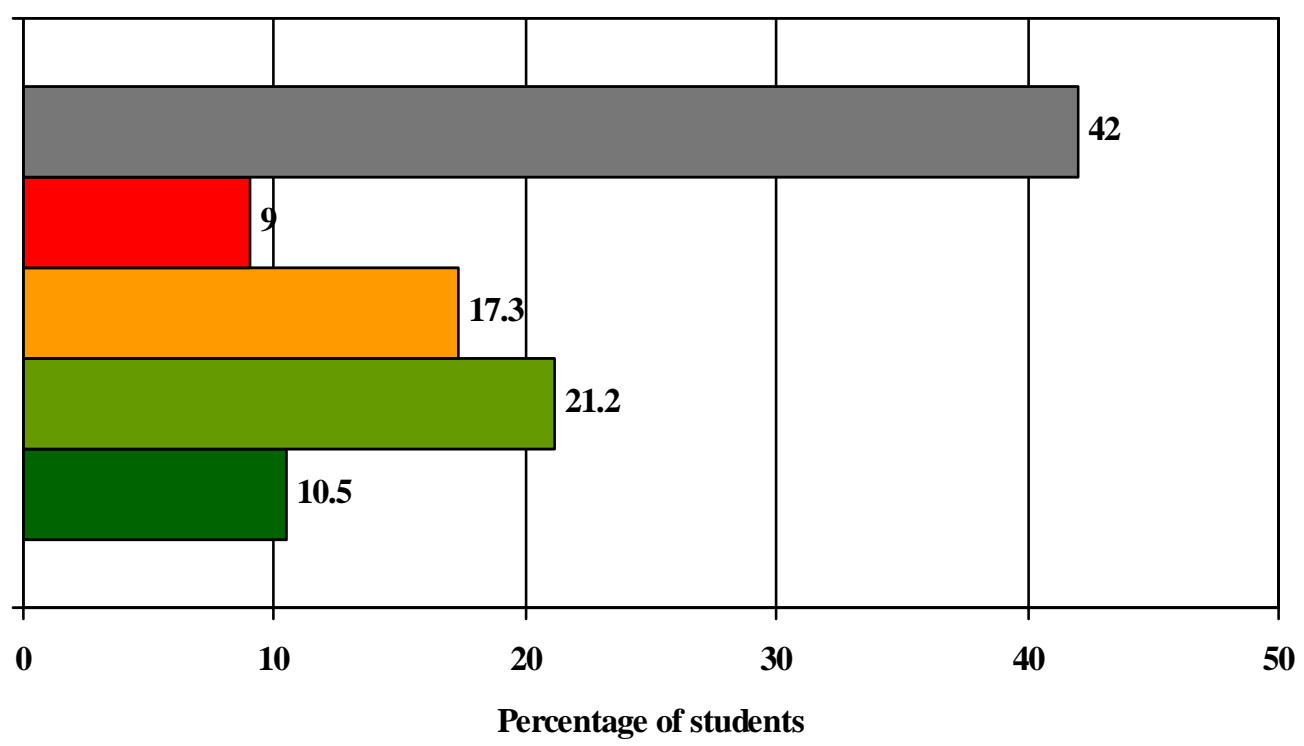

$\square$ Very useful $\square$ Useful $\square$ Of some use $\square$ Of little use $\square$ N/A

Not assessed online questions and tests were not available to $41.8 \%$ of respondents. At the same time majority of those who are offered online tests find them useful (54.5\%).

There were differences in the answers to this question due to year of study, gender and choice. Online questions and tests were more available to the students in year one and two, who feel most positive about them (59.2\% and 54.3\% respectively). This type of learning was available to only $37.4 \%$ of postgraduates, but the majority of them were also positive about its usefulness.

Similar to the answers to the previous question females were more positive than males in their responses - 58.1\% of females who have it available, find them useful, compared to $52.1 \%$ of males. Those who have chosen Economics as their first choice of degree were more positive about tests, than those who didn't $-56.6 \%$ and $48.3 \%$ respectively.

Students left both positive and negative comments: "Used in First year very successfully but lacking in 2nd year.”; "Annoying to access.”; "Available at your own leisure, came with the book."; "N/A - do not have this in my degree: not seen any."

Respondents suggest, "Online assessments to be done outside term would be useful to check on understanding of the course content."; "More online tuition with weekly questions to complete."; "Online tests are a good idea and could be used more as and when the student wants." 


\section{Q13.m. Materials posted by lecturer on course VLEs (such as Blackboard or WebCT) or website}

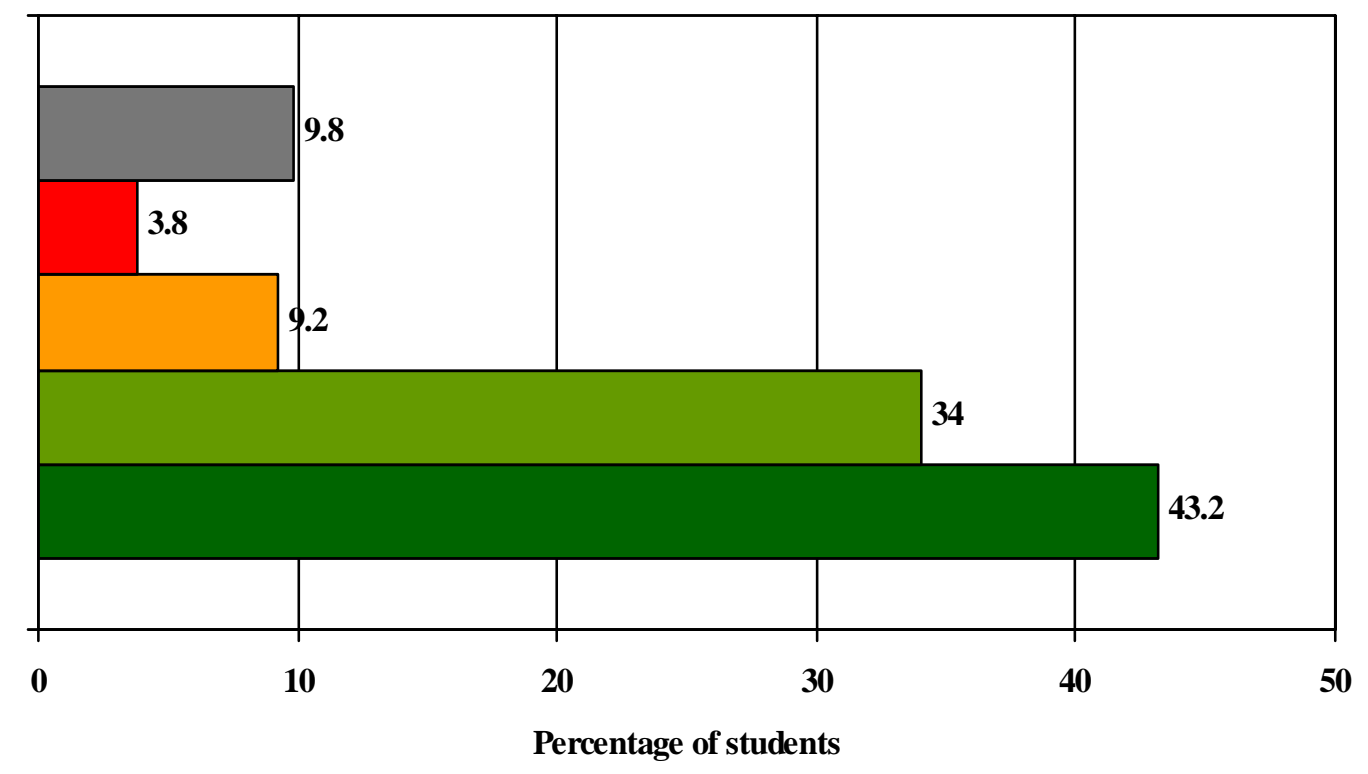

$\square$ Very useful $\square$ Useful $\square$ Of some use $\square$ Of little use $\square$ N/A

Materials posted by lecturer on course VLEs or websites are available to $90.2 \%$ of respondents. At the same time only 67.0\% of respondents replied in Q22 that their degree course make use of VLEs, so we can presume that the remaining $23.2 \%$ use materials posted by lecturer on websites. More than three quarters of them find these resources useful. There are differences in students' replies due to their year of study, age and first language.

Most positive about them were students from years one and two. More than every four out of five students in these years find materials on VLEs and websites useful. They also have the highest availability of these resources among all students groups: they are available to $93.7 \%$ of first year students and $93.0 \%$ of second year students. The non-availability doubles to $14.7 \%$ for year 3 and to $13.3 \%$ to year four students. It is also less available to postgraduate students $-15.9 \%$ of them said that they didn't have this option.

The non-availability of materials posted on VLEs or website doubles, as already mentioned for mature students of 26 and older. It is not available to $18.8 \%$ of them, compared to $8.9 \%$ of $18-21$ year olds and $8.3 \%$ of $22-25$ year olds. We have previously discussed the possible reasons for this.

Students with English as a first language were more positive about this question: 86.3\% of them, who have posted materials on VLEs available, find it useful, compared to $83.0 \%$ of non native English speakers.

In their comments to this question students mostly complain about resources that are not on the VLEs or website: "WebCT not used enough by some lecturers."; "Some lecturers are unwilling to post materials online, as they say it makes us lazy in 
lectures, but it is very difficult to write everything down and listen."; "Some lecturersvery useful, others has too little explanation or no content at all."; "There was not a lot (if any!) of extra material posted."; "Very few of the lecturers use blackboard!"; "Very useful when it is there, but some lecturers choose not to use it."

Additional students' comments on the usefulness of VLEs will be discussed later in the report.

\section{Q13.n. Communication tools (e.g. discussion board) in course VLES}

Communication tools in course VLEs were not available to one third of all respondents. Those who have them available don't find them particularly useful: three out of five find it only of some or little use. At the same time many students complain about the lack of interactivity in online learning.

There were differences in students attitudes due to their year of study, gender and age.

Communication tools were more available to students in year one and two $(74.2 \%$ and $68.9 \%$ respectively) and unavailable to more than half of postgraduates and to two out of five students in year three and four.

Females were more positive about its use, than males: $46.8 \%$ of those who have tools available found them useful, compared to $37.0 \%$ of males.

Communication tools were unavailable to nearly half of the mature students of 26 and older and to a third of 18-21 and 22-25 year olds. Mature students also have a biggest proportion of those who find it of little use $-38.6 \%$.

In their comments students either complain on the way communication tools are used, or complain that they are not available to them:

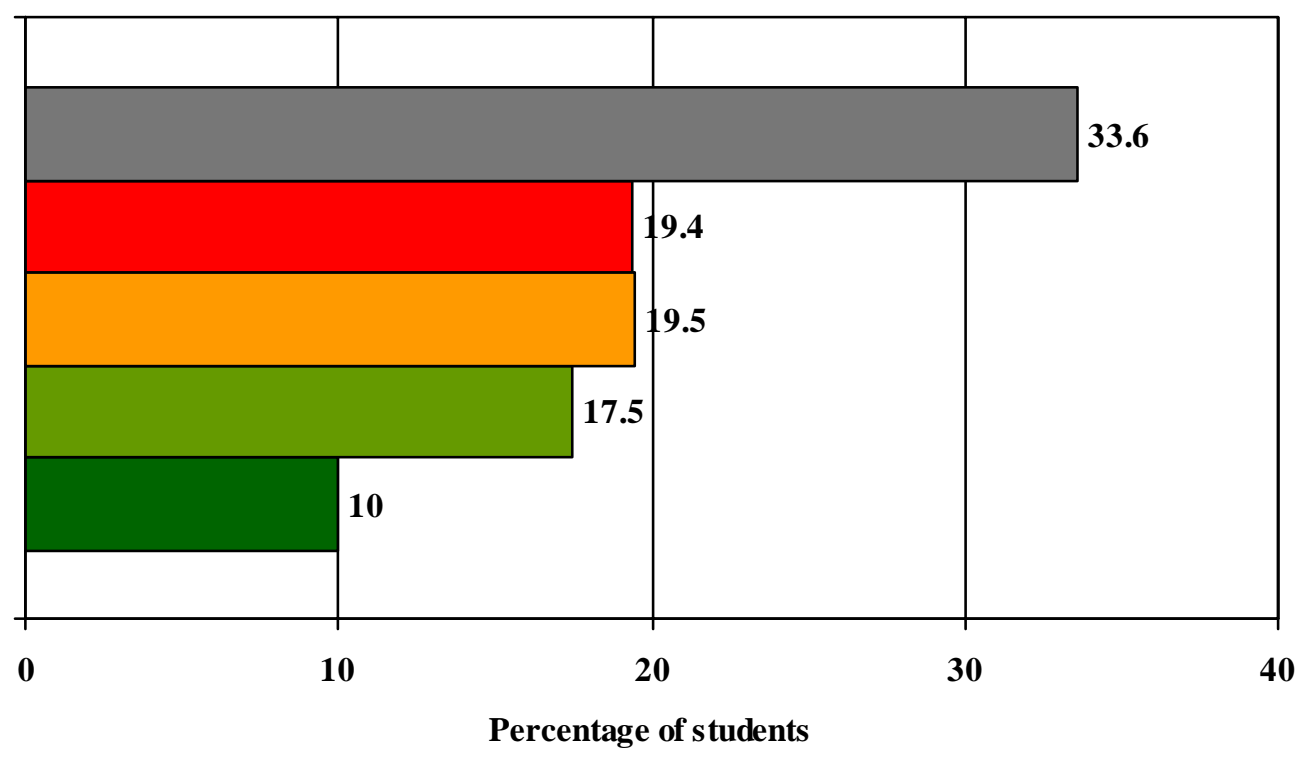

$\square$ Very useful $\square$ Useful $\square$ Of some use $\square$ Of little use $\square$ N/A 
"Completely useless. Most discussions are ridiculous."; "Could be useful, but is not really used by anyone.”; "Little use - rarely used by course members."; "If they are available they are not useful, because I did not know how to use it."; "Of little use: Appears students don't use this much - have never seen any information. "; "Of little use, as only one lecturer used it, but when used it was useful”.

Better use of VLEs is suggested - "In the first term, we had Maths and stats, and all lecturers put up detailed notes on blackboard for us to annotate. This made it very clear, and more importantly, meant we could pay more attention to what the lecturers were saying in lectures, rather than just copying down notes off the screen. The use of blackboard hasn't been used anywhere near as well for our Maths and econometrics subjects in term 2, and my personal performance in these subjects has suffered."

\section{On online assessment:}

\section{Q20.a.v. Online assessment}

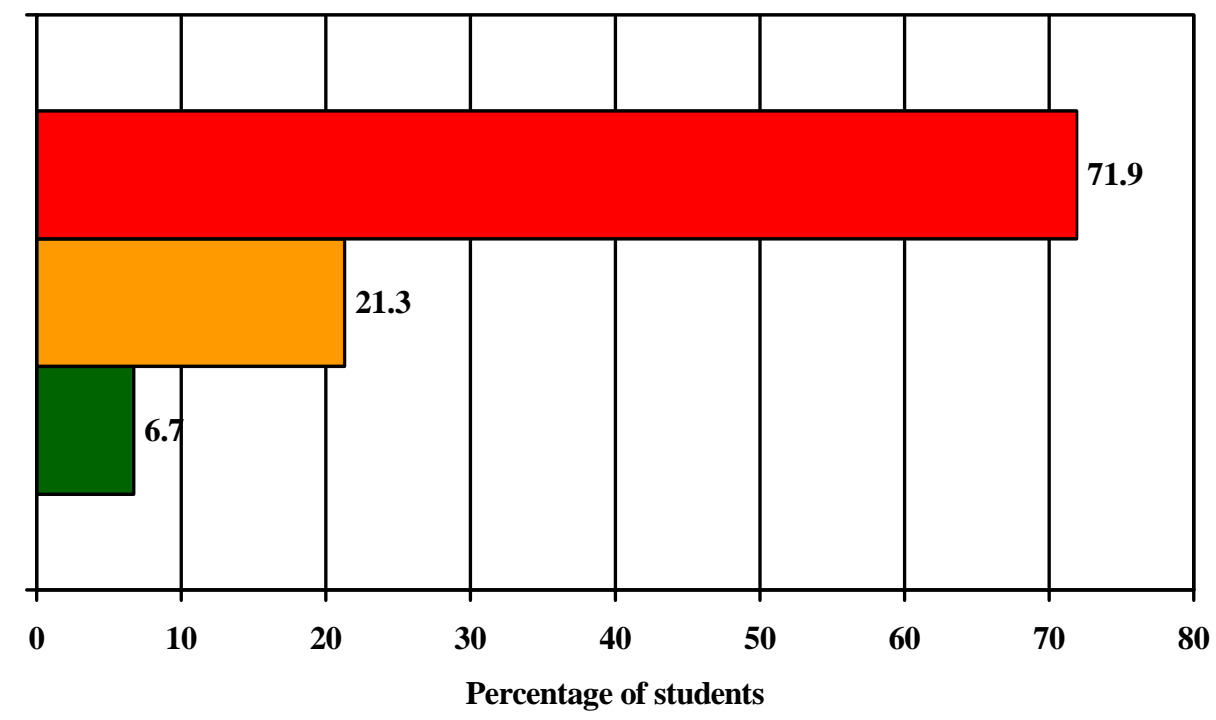

\begin{tabular}{|c|c|c|}
\hline$\square$ Frequently & $\square$ Occasionally & $\square$ Rarely or never \\
\hline
\end{tabular}

More than two thirds of respondents 'Rarely or never' have this type of assessment. It is used more often in year one, than in any other year: one in eight use it frequently and a quarter use it occasionally; more than $80.0 \%$ of students in year three, four and postgraduates 'Rarely or never' have it in their course. Students' comments include: "Online assessments to be done outside term would be useful to check on understanding of the course content."; "More online test with feedback and maybe an example of what a model answer would consist of."; "In a module in previous years, online tests were set every couple of weeks. These were not assessed but were obligatory and helped enormously as it encouraged you to look over previous work and gave more practice questions. This was than marked and the assessment left up with practice questions to go over as exam preparation.” 


\section{Q21. What Economics software is used on your degree? Q21.a. Please comment on how useful you have found the use of software}

The next group of questions are dedicated to the use of information technology in Economics education. We asked students what types of Economics software are used in their degree and invited comments on its usefulness. We also asked if their degree makes use of VLEs and how effective they are in supporting their learning. We also invited their comments on how this effectiveness could be improved. This question was answered by nearly half of the respondents.

Students' comments on the usefulness of Economics software should be considered in conjunction to their answers on what software is used in their degree.

1,665 respondents answered these questions and 36.6\% of them said that they didn't use any Economics software in their degree course. The majority of those who use Economics software use E views (24.0\%), STATA (19.5\%), SPSS (14.3\%), WinEcon (9.2\%), Minitab, Microfit, software from online workbooks and other unspecified software (sometimes VLEs are mentioned).

The majority of students find the use of Economics software on the course useful, though some students complain that not always enough explanations were provided.

Among the comments on Win Econ: "It is first years life saver.”; "Useful, but teachers shouldn't rely on it too much.”; “There are some online tests, and some summary for each topic - which I found quite useful."; "Very useful for world related exercise."

Comments on E views: "Has helped with the understanding of various econometric measures and their meaning in economic concepts."; "Very useful, although I would have liked to be taught to properly use them instead of occasionally using them in the way the teacher said."; "It is really useful, runs regressions much better than other software."

Comments on STATA: "Very useful for the analyses of microeconomic data."; "Fairly difficult to use, although you can apply statistical theory well using it."; "It is very useful, but hard to understand as a beginner."

Students' general comments on the use of software include: "Introducing Economic soft wares to student would be ideal."; "I think they should reduce course material from all modules and introduce soft wares used in investment, accountancy, and related business industries because every employer is looking for graduates with basic knowledge of the software used like Sage for accounting, Bloomberg, Style Research, Thomson One Banker and Datastream for investment.” 


\section{Q22. Do the modules /units on your degree course make use of a "Virtual learning environment" (VLE), such as Web CT or Blackboard?}

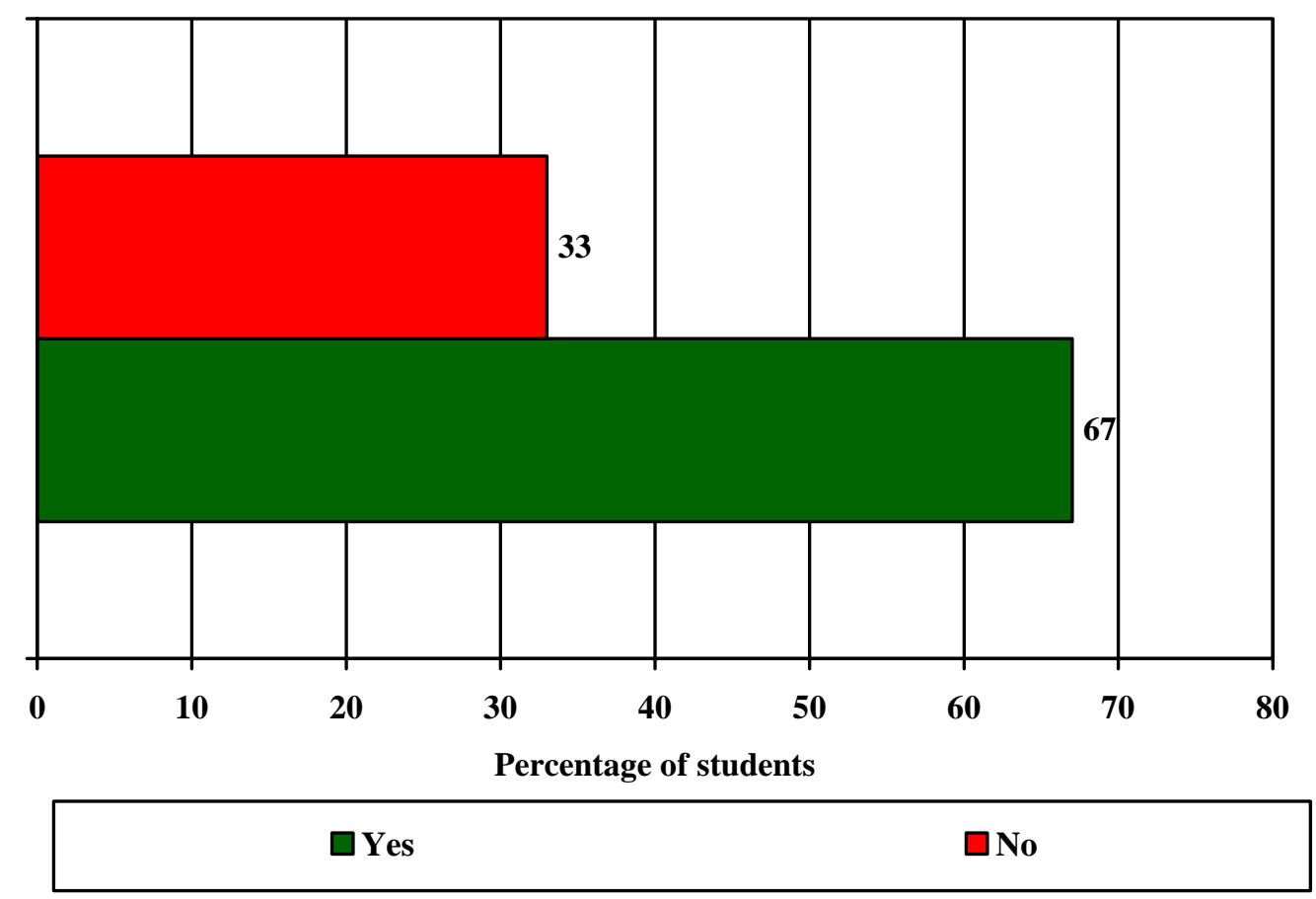

Two thirds of the students use VLEs in their degree, while one third doesn't. There are differences in the way various models/units make use of VLEs due to the year of study. It's use diminishes from the first year (73.8\%) to the second year (68.9\%) and all the way to postgraduate courses (56.1\%).

There were also statistically significant differences in the student's answers due to their age. Mature students of 26 and older however reported less positive - only $57.3 \%$ of them use a VLE in their course, compared to $67.5 \%$ of $18-21$ year olds and $69.3 \%$ of 22-25 year olds. It could be that higher proportion of mature students attend universities which don't use VLEs in teaching, but this may be also due to a lower level of computer literacy of the mature students, an issue already discussed in this report.

\section{Q22.a. If your course uses a VLE, comment on how effective you have found it in supporting your learning and how the effectiveness could be improved?}

This question was answered by nearly half of the respondents. Students consider VLEs to be effective tools, but the overall opinion is that it is not utilised enough "It's as effective as lecturers make it. Some put the whole course on there - that's very useful. Others put a reading list up and that's it.” Some lecturers are able to make better use of it by posting additional information and encouraging discussions, whereas others use it only as a resource for downloading lecture slides. 
The potential benefit of VLEs is that it provides access to a wealth of information needed by students; materials posted there improving understanding of the subject and enhancing communication between tutors and students and within the student groups. Among the comments: "VLEs gives us a better idea of what we actually know, not what we thought we knew."; "I have found it very useful to back up my notes and enhance my understanding."; "Lecture notes, model seminar problem answers, suggested reading and discussion forums online all support learning well. Online assessment is a mixed blessing. It's quick and easy but there is little room to get 'working marks' for any technical answers."

VLEs are also used as a tool for contacting tutors, though students' experience in this area varies: "Good way to communicate with lecturers useful as everything you need is in one place!"; "If we have problems we can email teachers for help, however it does mean we don't get the one on one support we need as some tutors have ridiculous office hours and do not email back for days. It could be improved by having feedback for students so we know how well we are doing."

Students suggest improving the effectiveness of VLEs by their more active use. Among the comments about VLEs: "It is very effective as it allows you access to past lecture slides and other notes and discussions."; "Website - lectures slides etc. Extremely useful: can prepare beforehand and can adapt your own notes."; "Very useful as can see answers to work set for workshops and can talk to others about any problems your having."; "Useful as recommended readings are available for download. Lecture handouts could be posted on Black Board as well.”

Students' suggestions for improvement include: "It has been effective in providing lecture and other materials. Further to this there is no other use. Improvements could be made through making use of other tools, such as discussion boards, possibly with lecturers allocating sometime for an online questions and answer session, but also for students to be encouraged to use discussion boards, as they are left unused."; "Only used for some modules. Would prefer more discussion boards."; "I found this very effective, but would have found it more so had ALL lecturers posted lecture material online for you to print out before the lecture, to save having to concentrate on writing notes down, and enabling you to listen to what they're saying more."; "It would be more effective if there was a discussion board so we could discuss issues arising with other students."

About 5\% of respondents complain about the use of VLEs in their department: "It is poor. Need better communication about what it is, and how to access it."; "Some lecturers don't give any handouts, we just have to go on Web CT to find them."; "I would say in terms of my learning it hasn't provided me with any educational benefits apart from providing access to lecture notes.”; "Blackboard, provided lecture noted and that is about it.” 